\title{
Contemporary Challenges Facing the Small Farmers in the Green Scheme Projects in Namibia
}

\author{
Martin K. Shapi ${ }^{1}$ \\ ${ }^{1}$ Social Science Division, Multidisciplinary Research Centre, University of Namibia, Windhoek, Namibia \\ Correspondence: Martin K. Shapi, Social Science Division, Multidisciplinary Research Centre, University of \\ Namibia, Windhoek, Namibia. E-mail: mshapi@unam.na
}

Received: November 17, 2016 Accepted: March 30, 2017 Online Published: May 6, 2017

doi:10.5539/sar.v6n3p1 URL: https://doi.org/10.5539/sar.v6n3p1

\begin{abstract}
The paper uses a combination of theory and both quantitative and qualitative evidence to demonstrate the significance and challenges of agricultural development in Namibian green scheme projects. For quantitative, a structured questionnaire to produce descriptive statistics was administered to 135 small farmers while eight (8) project manager who were interviewed at the studied schemes as key informant served as source of qualitative information that pin pointed out challenges and opportunities, faced by the small farmers in these schemes. The evidence points to the fact that although there are myriad of challenges, such as challenges related to production, access to efficient and effective market and access to credit faced by farmers, production and access to efficient and effect market challenges emerged as the most stumbling blocks to the optimal production and sales of small farmers' produce. Usually access to agricultural credit is seen as one of the major challenges of smallholder farmers in Africa. In this study access to agricultural credit was less seen as a major stumbling block to the smallholder farmers' productivity. This is attributed to the current farmers' agricultural credit support scheme in place between Agricultural Bank of Namibia (Agribank) and the government of Namibia.
\end{abstract}

Keywords: Green Scheme, small farmers, credit, market, production, Namibia

\section{Introduction}

Although agriculture is an essential economic activity in achieving poverty reduction (Mashindano, Kayunze, da Corta \& Maro, 2011), millions of Africans spend their entire lives poor, hungry, and malnourished, and majority of them live in rural areas and depend directly or indirectly on agriculture for their livelihood (Dorward, Kirsten, Were Omamo, Poulton \& Vink, 2009). Growth in agriculture in the developing economies can contribute significantly to Gross Domestic Product (GDP) foreign exchange earnings, employment creation, income generation, and poverty reduction. Notwithstanding its potential to drive economic growth and reduce poverty, African agricultural development remained vexed (Dorward et al., 2009). According to Binswanger and van den Brink (2005), Africa desperately needed poverty reducing economic growth at far higher level than it was happening at the time. Binswanger and van den Brink were of the opinion that for that to happen, there may be need for increase in private investment into agriculture and improved farmers' access to agricultural credit; in particular medium-term credit. However, since the late 1980s many countries and donor organizations stepped back from targeted agricultural credit program, given the extremely poor track record of such programs across the developing world. This developing world's agricultural development caricature was no exception to Namibia.

During the 1996 Food and Agriculture Organization (FAO) World Food Summit, commitments were made to increase investment in Africa's agricultural sector. However, during the 2002 FAO World Food Summit in Rome, a review of the actual results of increased investment in agricultural development indicated that investment in Africa's agricultural sector had declined over the past decade (Government of the Republic of Namibia [GRN], 2008). As a result, a regional meeting of African Ministers of Agriculture was convened in Rome where a decision to "expand irrigation by investing in irrigation infrastructure" was reached.

Agricultural development is well known for poverty reduction, employment creation, and income and wealth distribution. This is the case as it is through agricultural development that income generation of the poor is improved, and income is distributed across the society. It is through sound agricultural development that food security is improved as well as poverty and malnutrition is reduced. It is through agricultural development that food availability and affordability (via food-price effect) for both rural and urban poor is achieved. It is through 
agricultural development that employment creation is effected, as it is a labor-intensive sector (Bresciani \& Valdes, ND).

Moreover, the issue of increased investment in agriculture to trigger economic growth in developing economies re-emerged on the development agenda around 2007. The 2008 World Bank Report emphasized a need for developing countries to use the opportunities provided by agriculture in order to reduce poverty as it is seen as an engine for economic growth (GRN, 2008). Mashindano, et al., (2011) argued that trade and export of cash nuts and non-traditional items like mango and cut flowers were important routes of income growth for farmers in Tanzania.

It is for this reasons the Government of the Republic of Namibia, recognized that one of the most effective ways to reduce poverty and improve food security in the country is to raise the productivity of its agricultural resources on which poor people depend for their livelihood. As a result, cabinet decision No. 18th/06.08.02/004, approved the programme of investment and promotion of increased food production through irrigation schemes known as green scheme projects. Therefore, the main objective of the green scheme project in Namibia is to improve food production through irrigation in the country. This was envisaged to be realized through irrigation development, by bringing the private sector to remote and underdeveloped areas, thereby building local capacity in terms of production, marketing management and general development (GRN, 2008). It is for this reason that the Namibian green scheme premise to trigger agricultural productivity was a noble one, caveat to the existence of functional institutions that should coordinate, facilitate and enforce laws for efficient and effective market to be in place.

It is over a decade that the idea of green scheme was born and virtually 8 years ago since the revised green scheme policy was introduced, and tension between service providers and small-scale farmers, and between service providers and government, has been resurfacing in the local media. Most of the differences bordered around contractual issues or breach of contracts. The aim of this paper was to access the challenges faced by the small farmers in achieving the objective of the green scheme. This paper uses the data from institutional economics perspectives survey on selected green scheme projects in Namibia carried by Multidisciplinary Research Centre (MRC) in 2015 and present the contemporary challenges facing the small farmers in these schemes.

\section{The Green Scheme in Perspective}

The Green Scheme Policy defines the Green Scheme as the government programme aimed at increasing food production through irrigation production (GRN, 2008: III). This programme is designed to maximize irrigation opportunities along the maize triangle area of Grootfontein, Tsumeb and Otavi in the Oshikoto and Otjozondjupa regions as well as North Central and North Eastern regions of Namibia by utilizing the Kunene, Kavango and Zambezi rivers. In addition Green Scheme promotes the agro projects in the south of the country by utilizing the water from Orange River and dams such as Naute and Hardap and in the near future the Nickartal dam. The Green Scheme further seeks to harness the resources of government and other stakeholders in order to increase agriculture productivity and social development as envisaged in National Development Plan 4 (NDP4), Harambee Prosperity Plan (HPP) (a Presidential plan on poverty reduction) and the Vision 2030 strategy.

To-date, there are eleven (11) Green Scheme projects across the country (see table 1). These schemes vary in scope, size and focus. They range from as small as 150 hectares to 1263 hectares at Mashare and Etunda green schemes, respectively. The combined total area currently stands at 7641.6 hectares of which $56 \%$ of it ( 4282.6 ha) is under cultivation. They produce variety of crops from cereals (maize, wheat,), vegetables (tomatoes, onion, cabbages) and fruits (dates). 
Table 1. Various Green Schemes and their size in hectares

\begin{tabular}{|c|c|c|c|c|c|c|c|}
\hline Schemes & $\begin{array}{l}\text { Hectare under } \\
\text { production }\end{array}$ & $\begin{array}{l}\text { Hectares under } \\
\text { Commercial }\end{array}$ & $\begin{array}{l}\text { Hectares under } \\
\text { Medium } \\
\text { farmers }\end{array}$ & $\begin{array}{l}\text { Hectares under } \\
\text { Small farmers }\end{array}$ & $\begin{array}{l}\text { Orchard } \\
\text { Hectares }\end{array}$ & $\begin{array}{l}\text { Not under } \\
\text { production }\end{array}$ & Total \\
\hline Etunda & 963 & 483 & 120 & 300 & 60 & 300 & 1263 \\
\hline Hardap & 154.6 & 60 & 94.6 & & & & 154.6 \\
\hline Kalimbeza & 150 & 141 & & 9 & & 79 & 229 \\
\hline Mashare & 150 & 150 & & & & & 150 \\
\hline Musese & 450 & 450 & & & & 550 & 1000 \\
\hline Ndonga Linena & 580 & 421 & & 160 & & 419 & 1000 \\
\hline ORIP & 195 & 125 & & 70 & & 405 & 600 \\
\hline Shadikongoro & 390 & 300 & & 90 & & 200 & 590 \\
\hline Sikondo & 590 & 320 & 270 & & & 240 & 830 \\
\hline Shitemo & 420 & 420 & & & & 580 & 1000 \\
\hline Vungu-Vungu & 240 & 180 & & 60 & & 585 & 825 \\
\hline Total & 4282.6 & 3050 & 484.6 & 689 & 60 & 3358 & 7641.6 \\
\hline
\end{tabular}

Source: Agribusdev website and Author's calculations

Agribusdev $=$ Agricultural Business Development

\section{Generic Challenges in African Agricultural Development}

The ultimate objective for agricultural development in Africa is to achieve sustainable intensification with the adoption of new technologies that utilize purchased inputs to increase land and labor productivities (Dorward et al., 2009). While this is the objective for agricultural development in Africa, there are a daunting set of generic and usually mutually reinforcing problems that commonly impede such process in the poor rural areas that need them most. These problems include poor roads and telecommunication infrastructures, poor human health, lack of well-developed monetary economy; and thin market for agricultural inputs, output, and finances, despite significant direct and indirect dependence of the local economy on agriculture.

Nested within these general challenges facing poor rural areas, Dorward et al., (2009) highlighted a set of issues specific to agriculture and more so to small farmers. These issues include:

- The absence, in many cases, of market because of low purchasing power in the domestic market and poor access to global market caused by trade distortion (such as rich-country agricultural subsidies)

- Production and sale cycles that are long by the standard of other small businesses (exacerbating climate, pest, price, and transaction risks; leading to significant seasonality in labour use, cash flow, food availability, price and risk, and affecting the whole community and their economies);

- High returns to timely labor at periods of peak labor demand, so that often it makes sense even for poor farmers to supplement their own family labor with hired help if they have the means, even though they may seek to hire own labour out just a few weeks or days later;

- Insufficient allocation of labor to their own land during labor peak for some farmers because of poverty, forgoing valuable increases in their harvest, as shortage of food drive them to work for others.

- Small-scale individual input purchase that therefore have high transaction cost in situations where market are poorly developed and risky, even though technical progress and population pressure on land increase farmers' need for input.

- Technical choices that involve discontinuous switches between technologies and crops, with threshold prices and level of performance above (below) which certain activities are (are not) profitable or viable, with these threshold determining whether significant numbers of farmers demand or supply particular services or commodities.

- Need for seasonal financing of farmers' input purchases, raising issues of how such purchases can be financed and how the risks of such finance to poor farmers can be mitigated

- Use of significant share of output for subsistence, generating welfare but not cash, so that sales of output often fails to fully cover purchased input and labor costs; and

- Land tenure arrangement that affect farmers' ability to borrow, expand, or exist with a lump sum, by land-market transaction, and that also influence incentives for land improvement. 


\section{Methodology}

\subsection{Study Design and Sampling}

This study was a national one and focused only on government supported green scheme projects, which ran both commercial and small farmers component at the scheme. Over $60 \%$ of the schemes were visited. This ranged from the south where the annual rainfall is below $300 \mathrm{~m}$ per annum to the north central and northeast where the annual rainfall is between $450-600 \mathrm{~mm}$ per annum, respectively. These projects covered a total area of 7641.6 hectares of which 4282.6 hectares was under production for commercial, medium and small-scale farmers. Commercial farmers constituted big part of the land to the tune of 3050 ha followed by the small-scale farmers with 689 ha and lastly medium farmers with 484.6 ha. The study was conducted during the months of April, May and June 2015. The time of the study was selected so that it could give farmers a good chance to compare their production with the previous harvesting season.

A structured questionnaire was administered to 135 farmers at the eight (8) selected schemes. Since small farmers were few in some schemes except at Etunda where there were around 67 farmers, a probability sample was not considered in the sampling process at scheme with very few farmers. This meant that for quantitative, all farmers who were present at the scheme during data collection were interviewed. A farmer was only interviewed if he was involved in the production during both the preceding and the survey year. SPSS statistical package was used to generate descriptive statistics during the analysis of the quantitative data. For qualitative, eight project managers who were mainly responsible for commercial part of the scheme and also played mentorship and supportive roles to small farmers provided qualitative information.

\section{Results}

\subsection{Green Schemes and their Location}

One of the characteristics of national representation of a national project is its presence in all the fourteen political regions of the country. However, in terms of agricultural development projects in the context of Namibia, it depends on what the focus is on. If the focus is about livestock development then it could apply to all fourteen regions, but if the focus is about crop development, then it will not be applicable to all the fourteen political regions. This is mainly due to various reasons, but mainly the availability of water and fertile soil for crop production are the major determinants. Table 2 presents the regions where the schemes are situated and the proportion of the respondents per region. Apart from water availability and soil fertility the location of the schemes is also influenced by the type of crops suitable in that area.

The schemes in the south (Aussenkehr and Mariental) are mainly dominated by cash crops. These include; mainly grapes, tomatoes, cabbage, onions and dates at Aussenkehr, and Lucerne, tomatoes, cabbages and to a lesser extend onions at Mariental.

In terms of the number of farmers, many are found at Etunda Green Scheme in the Omusati region. Etunda has many farmers because it is one of the oldest schemes and has the biggest land available (1263 ha). However, the two Kavango regions house most of the schemes and this is because of the availability of fertile soil for most of crops and relative higher average rainfall. Zambezi is also a potential region in terms of this project; but at the moment it has only one scheme, focusing on rice production only.

Table 2. Green Scheme Projects, their Location and number of Farmers interviewed

\begin{tabular}{lllll}
\hline Region & Schemes & Total \# of Farmers & Respondents & \% \\
\hline Karas & Aussenkehr & 19 & 14 & 10.4 \\
Omusati & Etunda & 71 & 57 & 42.2 \\
Zambezi & Kalimbeza & 5 & 4 & 3 \\
Hardap & Mariental & 16 & 11 & 8.1 \\
Kavango East & Ndonga Linena & 25 & 21 & 15.6 \\
Kavango East & Shadikongoro & 13 & 11 & 8.1 \\
Kavango West & Sikondo & 9 & 7 & 5.2 \\
Kavango East & Vungu-Vungu & 10 & 10 & 7.4 \\
Total & & 168 & 135 & 100 \\
\hline
\end{tabular}

Source: Author's calculation 


\subsection{Gender and the Origin of the Farmers}

Generally women are considered to be the main sustainers of agriculture sector. This view resonates from the old school of thought which argued that men were more mobile than women in search of employment in non-farm sector. However, this line of thinking may not hold water in the modern society as more women are acquiring formal education, which is a gateway to formal employment. While this might hold water, from rural development perspectives, women still remain the main stakeholders in agriculture. Figure 1 presents the gender representation of the respondents on the green scheme projects. More than two thirds of the respondents were males in this study.

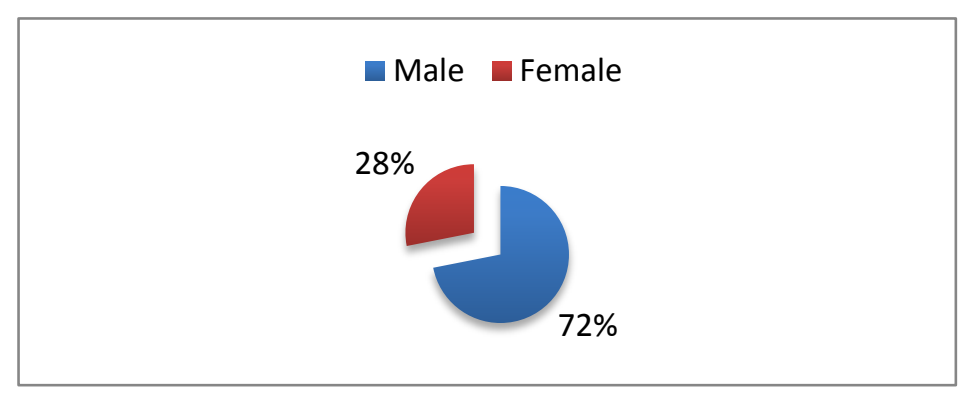

Figure 1. Gender of the respondents

One of the reasons that could explain the gender skewedness of the farmers in the green scheme project is the scheme's national representation. Beneficiaries are selected nationally hence women might be reluctant to leave their place of origin and work somewhere else due to various reasons such as family commitment, accommodation challenges amongst other reasons.

In terms of age, the average age of the farmers was 42 while the range was from 27 years as the youngest to 69 years as the oldest with the standard deviation of 9 confirming the existence of wide range of age difference among farmers.

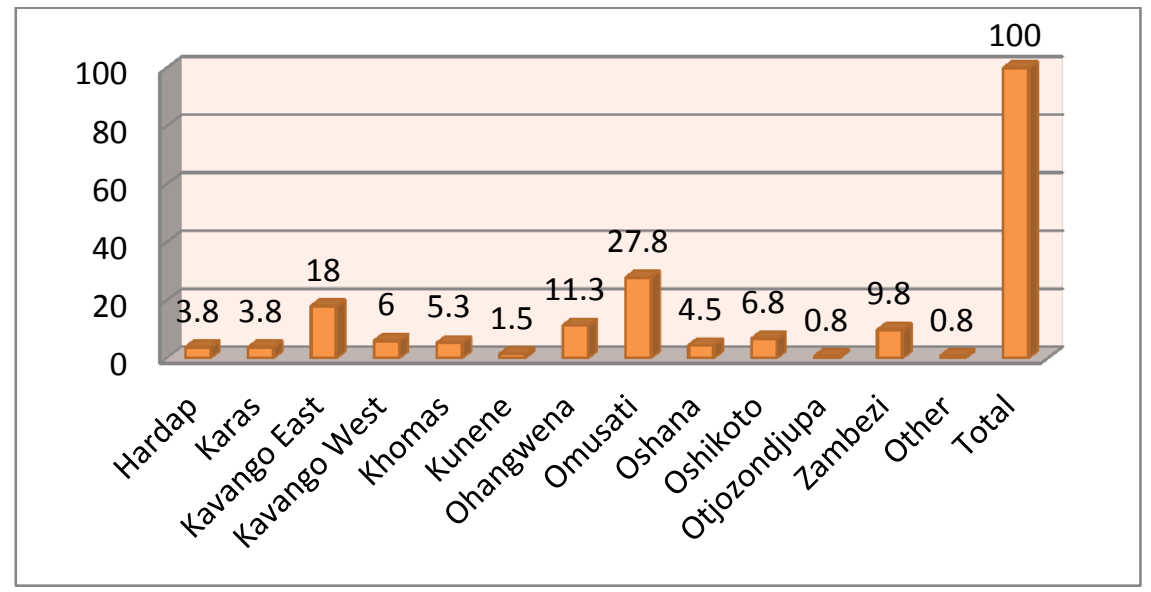

Figure 2. The origin of farmers (beneficiaries of green schemes)

Green scheme project is truly a national project as it is evident from figure 2 that virtually all the region in exception of Omaheke and Erongo regions have a representative on the project. It is no surprise that the two regions (Omaheke and Otjozondjupa) are not represented. This is the case because no crop production happens in these two regions, especially Erongo region. For Omaheke there are few islands of small-scale crop production here and there in the region but not that of significance. Worth noting is the presence of non-Namibian in the project which is very important in terms of agricultural skills transfer. It was discovered that the non-Namibian farmer was from Zimbabwe. Zimbabwe is known in southern Africa for its qualified human capital compared to most of southern African countries. It was also known for good agricultural production during its glory time before the negative impact of fast track land reform programme early 2000 on agricultural productivity.

\subsection{Educational Level of the Farmers}

The contemporary farming is not an art but it is a science. It is for this reason that a combination of both formal and practical education is essential for the modern farmers to farm successfully. This is imperative especially in 
African farming communities, as Africa has compounded farming limitations, be it soil fertility, climate change, access to credit, access to technology, pest challenges and thin agricultural market. Figure 3 presents farmers' level of education.

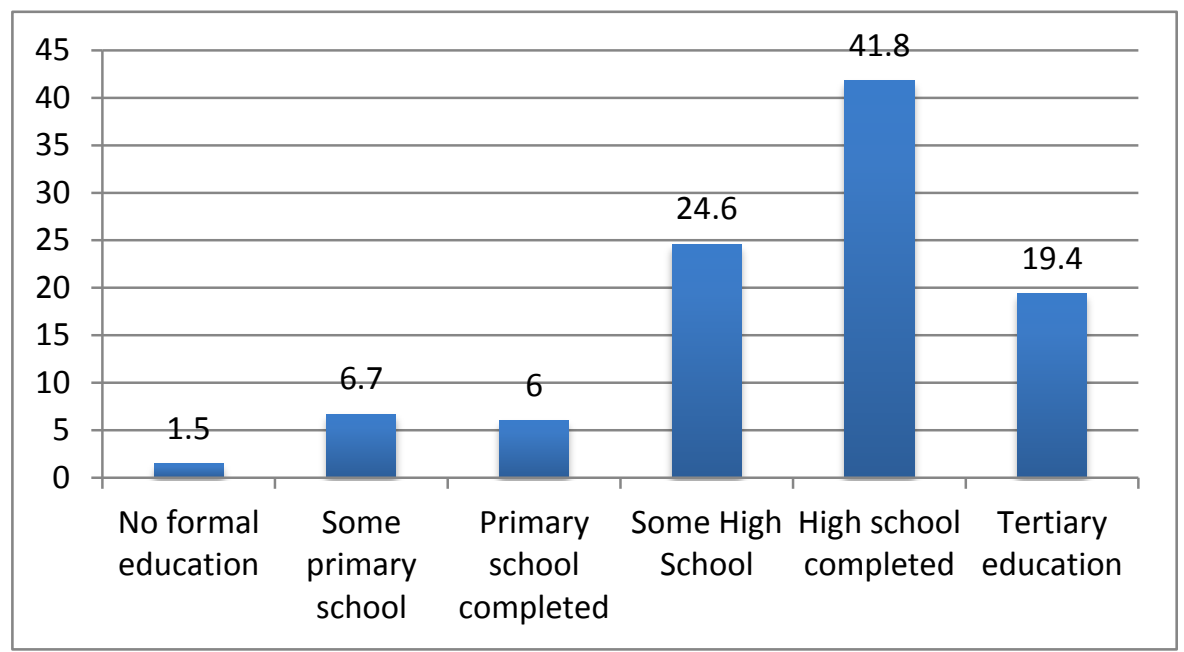

Figure 3. Farmers' level of education

It is evident from figure 3 that the majority of farmers completed some or high school (66\%) and virtually $20 \%$ had tertiary training. As stated earlier, this is a positive indication of successful farming enterprise as well above $60 \%$ of farmers is assumed to have acquired basic formal education which is a key to modern successful farming. This formal education makes a farmer to quickly grasp and internalize any additional training she or he may receive. Figure 4 presents farmers' agricultural training skills. Comparing general formal education and agricultural training skills received by farmers, $86 \%$ of the farmers confirmed to have received agricultural training.

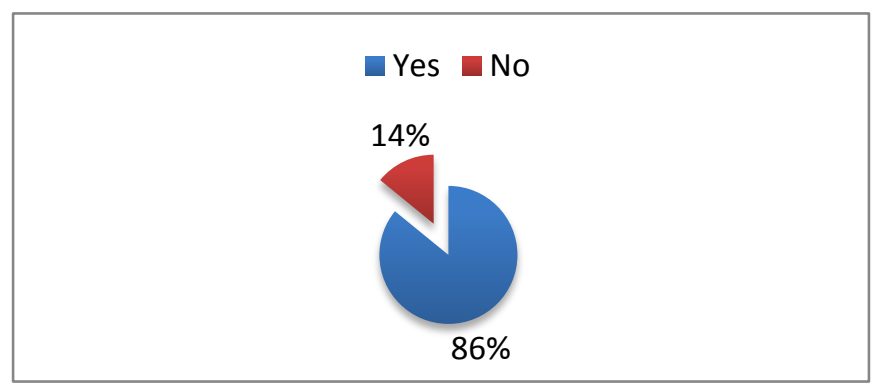

Figure 4. Agricultural training skill

The higher number of farmers indicating to have received agricultural training is attributed to the fact that after the beneficiaries succeed in getting into the programme, they are expected to go through agricultural training prior to their deployment in various schemes where unoccupied plots are available. This training is carried out by the line ministry to successful candidates before the farmers receive their allotments. This is confirmed by table 3 , which indicates that $70 \%$ of the farmers have been trained by government. Close to one third of the farmers indicated that they received training from other service provider than the government. A close look at others revealed that organization such as Agrifutura, Univesity of Namibia (UNAM), Namibia University of Science and Technology (NUST), Women's Action for Development (WAD), Namibia Development (NDC), own private training companies, constituted this category.

Table 3. Providers of agricultural training

\begin{tabular}{lll}
\hline Provider & Respondents & $\%$ \\
\hline Government & 84 & 70 \\
Service Provider & 7 & 5.8 \\
Other & 29 & 24.2 \\
Total & $\mathbf{1 2 0}$ & $\mathbf{1 0 0}$ \\
\hline
\end{tabular}




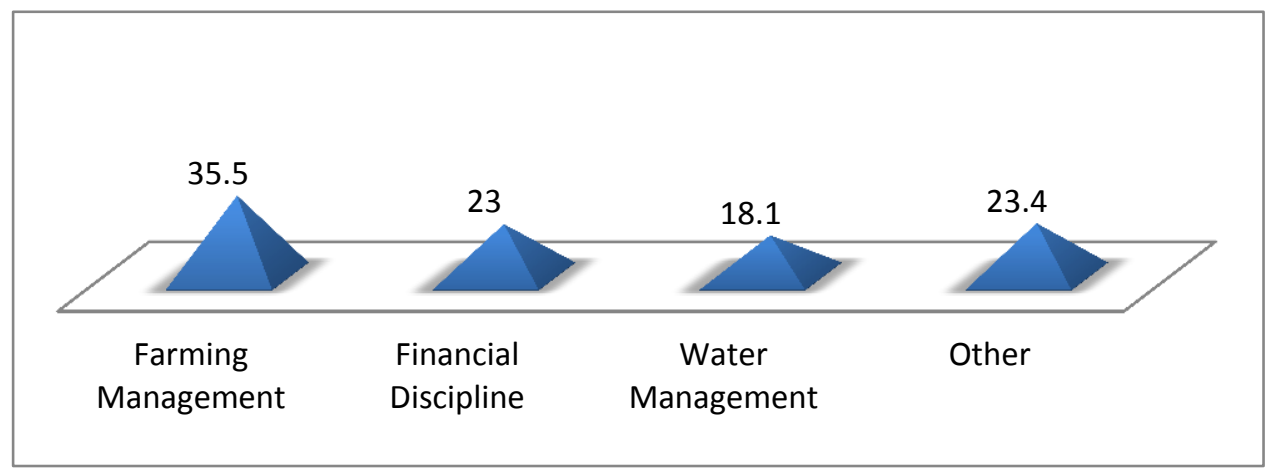

Figure 5. Areas of training the farmers received

Figure 5 indicates the various areas of training in which the farmer received the training. It is evident from the figure that farmers mainly receive general farm management training (35.5\%), followed by financial management $(23 \%)$ and water management training $(18.1 \%)$. There was a big portion of farmers who reported to have been trained in other areas (23.4\%). These included administration, agronomy, pest control, fertiliser application, marketing and how to grow grapes and rice.

\subsection{Average Kilograms of Various Crops Produced}

Average kilograms of production per hectare are one of the measures used to get an indication of the productivity of a farm. Table 4 show the mean, minimum and maximum kilograms of various crops produced by the farmers during the last planting season. Of paramount on this is the average of maize and grapes produce per hectare.

Table 4. Average kilograms produced for the last harvest

\begin{tabular}{lllllll}
\hline Crops & Respondents & Mean & Median & Std Deviation & Minimum & Maximum \\
\hline Maize & 101 & 40827.9 & 18000.0 & 86442.9 & 400 & 800000 \\
Pearl Millet (Mahangu) & 1 & 2000.0 & 2000.0 &. & 2000 & 2000 \\
Sorghum & 0 &. &. &. &. &. \\
Butternut & 53 & 12026.9 & 5000.0 & 22149.8 & 60 & 150000 \\
Tomatoes & 43 & 126928.6 & 1000.0 & 761757.9 & 0 & 5000000 \\
White grapes & 14 & 19924.3 & 18389.8 & 16389.6 & 1000 & 68000 \\
Red Grapes & 2 & 13500.0 & 13500.0 & 2121.3 & 12000 & 15000 \\
Potatoes & 3 & 30500.0 & 45000.0 & 25114.7 & 1500 & 45000 \\
Sunflowers & 0 &. &. &. &. &. \\
Wheat & 49 & 23426.9 & 15000.0 & 41000.1 & 250 & 225000 \\
Onions & 35 & 7502.6 & 3000.0 & 12597.5 & 0 & 55000 \\
Cabbage & 49 & 15953.4 & 6000.0 & 42745.3 & 60 & 300000 \\
Watermelon & 28 & 185186.8 & 2900.0 & 943658.9 & 100 & 5000000 \\
Carrots & 21 & 6691.5 & 700.0 & 10965.0 & 0 & 45000 \\
Beetroots & 7 & 5222.9 & 4000.0 & 5497.1 & 0 & 15000 \\
Rice & 4 & 5887.5 & 5750.0 & 536.0 & 5450 & 6600 \\
Green pepper & 16 & 2440.6 & 687.5 & 3926.6 & 0 & 15000 \\
Pumpkin & 9 & 42888.9 & 8000.0 & 96954.2 & 1000 & 300000 \\
Sweet potatoes & 36 & 4992.1 & 1682.5 & 8369.9 & 0 & 45000 \\
Gem squash & 10 & 5920.0 & 3500.0 & 6617.8 & 100 & 20000 \\
Ground nuts & 10 & 1245.0 & 675.0 & 1499.9 & 0 & 4000 \\
Lucerne & & 7474.0 & 3570.0 & 7484.4 & 80 & 18000 \\
Sweet melon & 4 & 5725.0 & 5950.0 & 4895.8 & 1000 & 10000 \\
Dates & 5 & 1853.0 & 1200.0 & 1737.4 & 50 & 4000 \\
\hline
\end{tabular}

The focus on maize and grapes resonate from the fact that most of green scheme beneficiaries are given 3 hectares of land for this purpose with a exceptions of very few farmers with between 6 - 9 hectares, of land and the seven (7) and eight (8) farmers at Sikondo and Etunda, respectively who were given 30 and 12 hectares of land, respectively. These 7 farmers are usually referred to as medium-scale farmers. The data in Table 4 under maize include the production of 7 and 8 farmers with 30 and 12 hectares at Sikondo and Etunda green schemes, 
respectively. The inclusion of these farmers affects the mean and maximum kilograms produced. Furthermore, grapes are only produced at Aussenkehr and the aggregate shows only for these farmers at that scheme. However, general conclusion can be made that on average farmers produce 13.6 and 2.1 of tonnes per hectare for maize and grapes respectively (author's calculation). Standard deviation of 86442.9 and 2121.3 for maize and grapes, respectively are indications of huge difference in farmers' productivity in several schemes. Similarly, the same trend is observed in other crops. Unfortunately, green scheme farmers cannot be compared to non-green scheme farmers in the area as non-green scheme farmers in area mainly focus on millet production. Nevertheless, a general conclusion is that green scheme farmers produce more (13.6 tones) per hectare compared to non-green scheme farmers who produces on average 1.5 tons of millet per hectare. It is for this comparison that it is safe to conclude that green scheme project has the potential to increase productivity per hectare, which could lead to increase in food security and improved income for the farmers.

\section{Challenges Which Hinder Farmers' Optimal Production}

Usually, small farmers in the developing countries face a myriad of challenges, which impede their optimal production and in turn negatively affect farmers' income generation and food security. In the case of Namibia lack of water availability throughout the year and poor soil fertility are the major hindrances to crop farmers to attain optimal production. However, in this study the two challenges were not considered because of the nature of the study, which focused on irrigation projects. Inputs and other related challenges that negatively affect optimal production, access to market and agricultural credits were the focus of this study. The proceeding section will elaborate more on these challenges.

\subsection{Production Related Challenges}

Druilhe and Barreiro-Hurle (2012) indicated that failure in agricultural input markets are common in developing countries and are a major constraint to productivity growth. They further indicated that farmers in sub-Sahara African face acute constraints, with poor output price incentives, higher fertiliser price, lack of liquidity/credit and lack of knowledge. Farmers were asked as to whether they encounter any challenges that impede their optimal production. Ninety-six percent of farmers confirmed to have encountered production challenges. Table 5 presents production challenges, which were considered in the study. Higher input cost was the number one production challenge highlighted by $14 \%$ of the respondents, followed by higher prices of fertilizer (13.1\%), electricity bill $(11.3 \%)$, pest $(11 \%)$, water bill $(7.7 \%)$ and inadequate land $(7.1 \%)$. Long distance from input market and lack of implements were reported to be production challenges by 5\% of respondents each. Combining all input related challenges (lack of labour, water and electricity bills, and fertilisers) $48 \%$ of production challenges were input related.

Inadequate land affecting optimal production is in line with Dorward et al., (2009) who asserted that land tenure arrangement affects farmers' ability to borrow, expand or exit with lump sum, by land market transaction, as well as influences incentive for land improvement from the farmers' side. There were a higher number of respondents who indicated other challenges as hindrance of optimal production, and these include sandy soil, land is salty (at Mariental), water supply breakdown, seed and fertilizers come late, higher price of seeds and fertilisers and late arrival of ploughing services.

Table 5. Challenges, which hinder optimal production

\begin{tabular}{lll}
\hline Production Challenges & Respondents & \% \\
\hline Higher Input cost & 73 & 14.0 \\
Long distance from input market & 26 & 5.0 \\
Higher Interest & 25 & 4.8 \\
Lack of implements & 26 & 5.0 \\
Higher water bill & 40 & 7.7 \\
Higher electricity bill & 59 & 11.3 \\
Inadequate land & 37 & 7.1 \\
Lack of clear ownership of land & 8 & 1.5 \\
Lack of Labour & 10 & 1.9 \\
Fertilizer & 68 & 13.1 \\
Pest & 57 & 11.0 \\
Other challenges & 91 & 17.5 \\
Total & $\mathbf{5 2 0}$ & $\mathbf{1 0 0 . 0}$ \\
\hline
\end{tabular}




\subsection{Market and Access to Market}

Mashindano et al., (2011) argued that market access and attractive prices for producers transmit growth to poverty reduction. One of the green scheme's objectives is to diversify agricultural production and products for the domestic and export markets (GNR, 2008). According to the green scheme policies farmers should sell their produce via service provider. For this reason the government established Agro-Marketing and Trading Agency (AMTA) to coordinate and market the agricultural produce from the green schemes in the whole country. This meant that farmers were only expected to produce and not to worry where to sell their produce. It was for this reason the study wanted to know how efficient this arrangement was in terms of seeing farmers produce being sold and sold at a fair and reasonable price, which will make farmers satisfied. Figure 6 presents various market places where the farmers sell their produce.

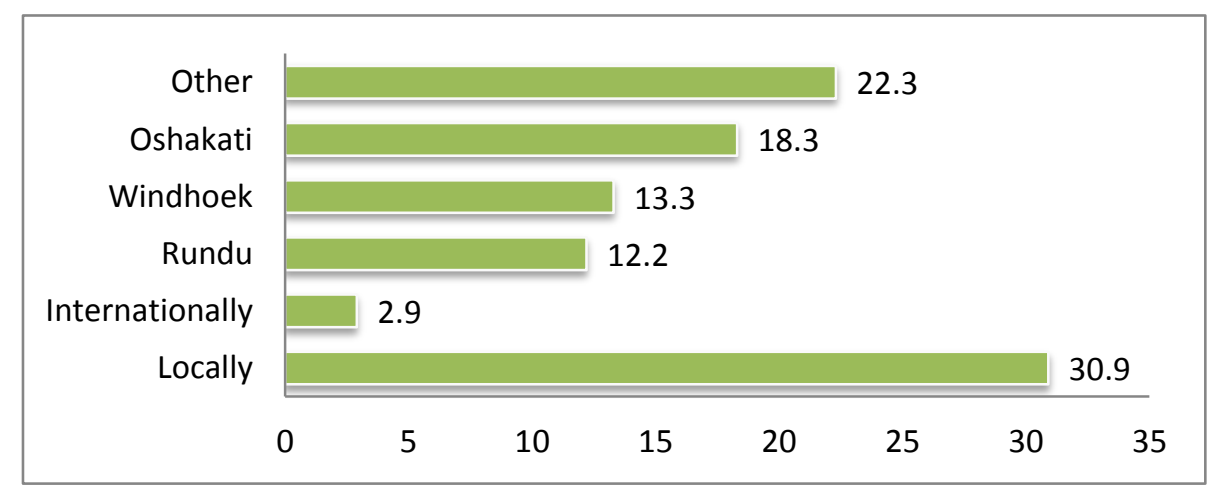

Figure 6. Various market places for green scheme produce

One third of the farmers reported to have sold their produce locally, meaning at the farm gates or areas nearby farms. Only about $3 \%$ of the farmers indicated to have sold their produce outside the boarders of Namibia. These farmers are mainly the grape farmers as grapes are mainly produced for foreign market. Close to $20 \%$ of the farmers indicated that they sell their produce in Oshakati. These farmers are mainly from the Etunda Irrigation Scheme, but some few farmers from other schemes also sell their produce in Oshakati. This is so because Oshakati is one of the biggest towns, hence better market potential exists. The same reasoning applies to the 13.3\% of the farmers who sold their produce in Windhoek. Worth noting, 22.3\% of farmers indicated other market places. These included mainly Agro Marketing Trade Agency (AMTA) a vegetable hubs in the town of Ongwediva, and Rundu, nearby towns of Outapi, Oshikango, Ondangwa, Ruacan, Keetmenshop, Katima Mulilo, Tsandi and Omuthiya featured prominently. It was a little bit surprising to see that AMTA, as a designated market for farmers, not featuring prominently instead it fell under other markets as it (AMTA) was supposed to be the major market destination of farmers to sell their produce. However, a wide spread of local market is an indication that with well coordinated supply chain, there exist a thriving local market which is usually ignored in African agricultural development.

Fafchamps (2004, as cited in Dorward et al., 2009) highlighted that market exchange in Africa is much more costly, cumbersome, time consuming, and unpredictable than elsewhere because of the following reasons:

- Search cost are high because of the large number of participants (no printed catalogs, no phone listing, yellow pages, or the like)

- Most transactions are small and cash based with limited and highly personalized credit arrangements, because contracts are difficult to enforce.

- The quality of goods and services is uneven, and as a result traders choose to inspect the quality of products at each transaction

- Few, if any, government standards are available to facilitate quality verification, hence it is difficult to distinguish bona fide producers from fly-by night operators selling inferior products

- Because of no proper personal identification systems, the transparency problem also applies to the selection of customers.

The same question as with regard to factors that impede optimal production was asked to the farmers as to whether they were encountering some market challenges. Ninety percent of the farmers were in affirmation that there existed some market and marketing challenges. Figure 7 presents the market challenges faced by the green scheme farmers. 


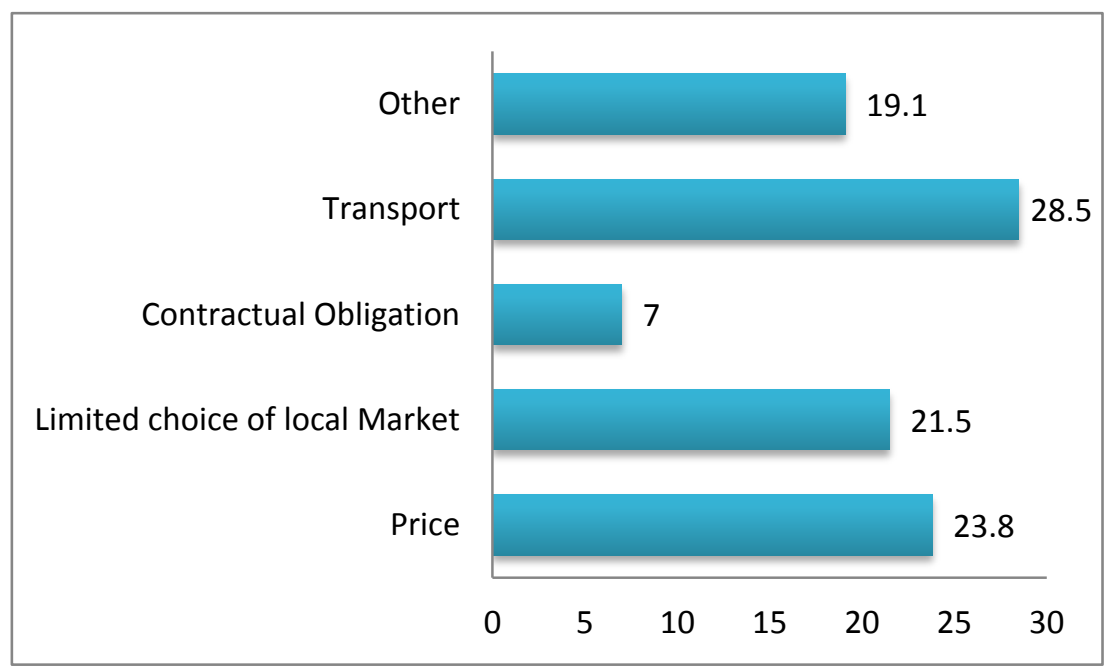

Figure 7. Some of the impediment to optimal sale of farmers' produce

Most of the schemes are kilometers away from the urban center where good purchasing power is available. This will require efficient, cheaper and reliable transport to transport the quantity and good quality of produce to marketplace on the right time it is needed. $29 \%$ of the farmers complained about transport as a major challenge to their optimal sale of their produce, followed by price (23.8\%), limited market choice $(21.5 \%)$ and last contractual obligation $(7 \%)$. Nineteen percent of farmers indicated other impediments for optimal sale of their produce which included over supply of the market due to the production of the same produce at the same time, farmers are price takers and AMTA is the price maker, and AMTA's inability to expand market for the farmers, hence many of farmers produce get spoiled at AMTA's hub.

\subsection{Access to Credit}

Credit usually involves the risk of borrower default, and lenders therefore pursue various procedures to reduce default risk and to minimize the losses, which may be incurred in the case of default (Feder, Onchan \& Raparla, 1988). Therefore, according to Stiglitz and Weiss, (1981) cited in Feder et al., (1988) screening potential borrowers according to creditworthiness criteria and credit rationing are two common policies adopted by lenders facing default risk. Feder et al., (1988) further notes that another universal procedure designed to increase the lender's expected profitability from a loan transaction is the utilisation of collateral and guaranties. It was for this reason that this study wanted to know the source of credit for the farmers and the challenges therefore to access them. Figure 7, presents the various sources of financial support of farmers.

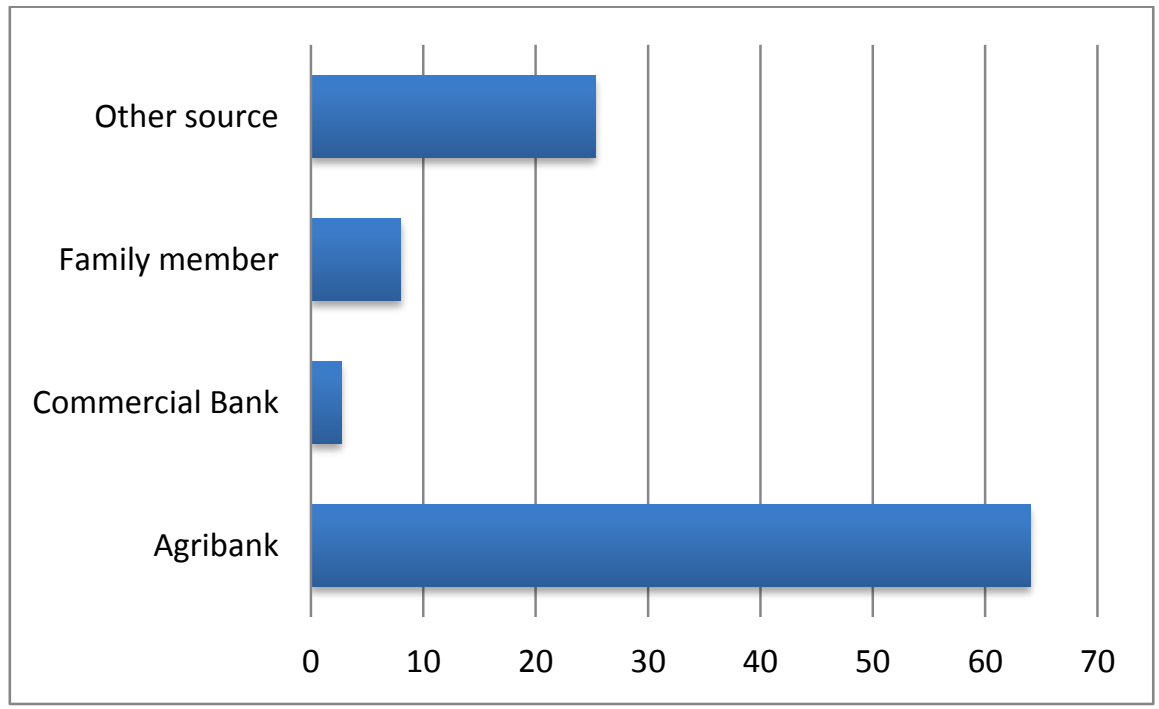

Figure 7. Source of financial support for the farmers 
Being a green scheme beneficiary puts a farmer in a better position to access production loan from Agribank. This is deliberate arrangement between government and Agribank to support green scheme farmers to access production loans. In this arrangement government serves as a security for farmers to Agribank. This smart arrangement for farmers to access agricultural loan is what Binswanger and Deiniger (1997), and Binswanger-Mkhize (2015) described as some of the factors that explain variations in agricultural development in developing countries. However, farmers' financial needs keep on increasing every day hence, never satisfactorily met. Figure 7 presents sources of financial support of farmers. It is evident from Figure 7 that $64 \%$ of the farmers confirmed to have acquired production loan from Agribank. It is worth noting that there exist a strong social link and support between and among family members such that $8 \%$ of the farmers reported to have financial support from family members when needed. It is also good to see several sources of financial support including commercial banks assisting farmers. However, it is very worrisome that $25 \%$ of farmers claimed to get financial support from other sources. Agribank should make sure that all creditworthy farmers should access agricultural credit from them, as their interest rate is plausible for the poor farmers.

Some of the farmers complained about Agribank's delay in processing and approving loan. They said that if farmers asked production loan via service provider it took months before they got the input. Consequently, this made them to solicit funds from commercial banks. However, Ayelew, Deininger and Duponchel (2014) highlighted that such limited formal credit market activity is not uncommon in rural areas of developing countries, due to a limited outreach of the formal system. To access extra liquidity, rural households are then restricted to borrow in the informal and the semi-formal sectors (Ayelew, et al, 2014). This could be explained by the $35 \%$ of respondents who said that they get credit from other sources. Binswanger and van den Brink (2005) listed the impediment for farmers to access credit in rural Africa. These impediment include the following:

Low demand for credit - One reason for the failure of many well-intended agricultural credit programs stems from a fundamental, and economic rational, lack of demand, given the incentives farmers face. For instance, in land abundant situation, soil fertility conservation becomes cost effectively achieved by shifting cultivation under long fallow system, leading to a lack of demand for the types of input associated with agricultural intensification. Low demand for credit can be the result of low profitability of agriculture and the high transaction cost and transport cost farmers face. And in other cases, profitability can also be low because of the existence of monopolies and monopsonies in inputs and output markets.

Heterogeneity - In Sub-Saharan Africa in particular, extreme heterogeneity raises transaction costs and aggravates asymmetric information problem and resulting in the moral hazard problem. For instance, even within a particular agro-climate zone, differences between villages, farmers and plots can be great. This affects the same way the productivity of the farmer, hence the borrower has to be careful in lending the money.

Seasonality - The agricultural marketing chain from farmer to market, is characterized by severe seasonally problems as they follow stylized description. At the start of the growing season, farmers want to borrow, or withdraw their saving to buy inputs. This leads to liquidity crunch at local level financial institutions. Saving will be withdrawn en masse while no new deposit will be made available out of which to lend.

Covariant risks - Co-variant risks imply low financial intermediation. Potential borrowers in the farm economy typically face common shocks. Co-variant risk from a number of sources (for instance- the weather, pest, prices). They therefore have great difficulties in guaranteeing credit for each other. And their problems become especially severe when there are several common shocks in a raw.

Moral hazard - Moral hazard results from asymmetric information. The term "moral hazard" describes the opportunistic behavior of a borrower who exploits the lack of information by the lender. With respect to farmers, the type of moral hazard and asymmetric information is typically associated with farming, is best illustrated by the popular caricature of the farmer, who is always poor, eternally subject to bad weather, or when the weather is good bad price or exploitative traders. Moral hazard is a constraint to lending to individual borrowers any where. But in rural areas it is compounded by heterogeneity and high risk.

Inability of crop insurance to solve the combined problem of co-variant risks and moral hazard - Crop insurance programs have long been advocated to overcome the riskiness of lending in rural areas, usually in the form of insuring loans or service payment. However, crop insurance can only play a limited role in reducing agricultural risk facing farmers, because crop insurance programs face the same problems that agricultural credit face: covariant and moral heterogeneity, asymmetric information, risks, hazards.

Difficult of mortgage-based lending based on individual farms, as well as group assets - Mortgaging of farmer or group assets is a well-known solution to improve repayment incentives. But the international evidence shows that there is little agricultural term credit in developing countries based on mortgaged individual farms. The 
reason for the death of mortgage-based agricultural lending may simply be related to low population density and the absence of private and tradable property rights in land.

Worthy noting is that compared to production and market challenges faced by farmers, only $53.3 \%$ of the respondents who agreed to have some challenges with agricultural credit, indicated to have encountered such challenges as compared to $96 \%$ and $90 \%$ of production and market challenges respectively. Figure 8 presents the factors making access to credit awkward for farmers.

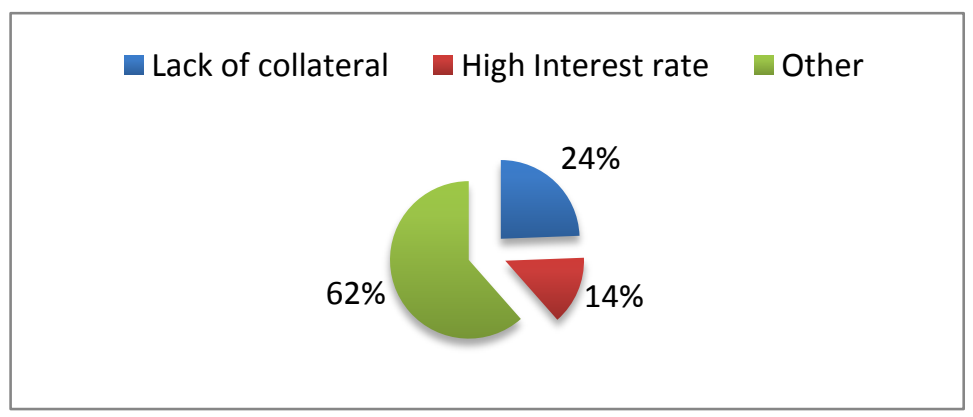

Figure 8. Factors making access to credit awkward for farmers

Of those who confirmed encountering problems with accessing credit, $24 \%$ highlighted lack of collateral as the most problem they encountered in accessing credit followed by high interest rate even though Agribank interest rate is believed to be as lowest as 7\% prime rate. The big proportion (62\%) of respondents alleged that they encounter other problems in terms of accessing credit. These included mainly, if the farmers owed the bank one would not access additional loan, and delay in the processing and approval of the loan.

\section{Conclusion}

Focusing on maize production as a staple food in the northern part of the country, Government's move to promote investment in irrigation agriculture in areas where water supply is ample to trigger increased food production as well as food security is well on course. Using Millet as a proxy to maize green scheme farmers produce more (13.6 tones) per hectare compared to 1.5 tones of millet per hectare for non-green scheme farmers in the same area. Therefore, green scheme can be regard as one of the effective way of reducing poverty rate, which stands at 28\% in the country (Namibia Statistic Agency [NSA], 2012). Most of the farmers had high school education level, and about $20 \%$ of them had tertiary education. In terms of agricultural training above $80 \%$ of the farmers received agricultural training.

Production and marketing challenges featured most as compared to access to agricultural credit challenges faced by smallholder farmers in the Namibian green schemes projects. In terms of production challenges, they mainly had to do with input cost such as water and electricity bills and fertilizers as well as pest and inadequate land. With regard to marketing, the transportation of farmers' produce to market places, low prices offered to the produce and over supply of produces were the major marketing challenges reported by farmers. It was pleasing to note that local market for farmers' produce existed in the area. In terms of accessed to agricultural credit, over $70 \%$ of farmers indicated not to have problem with accessing agricultural credit. This is a good indication that Agribank is living to its expectation by facilitating farmers to access agricultural credit at a low interest rate. However, the bank is urged to make use of its comparative advantage of being the only agricultural bank to provide efficient, affordable and effective services to the farmers as farmers complained the cumbersome process of the bank before a loan is approved.

\section{Acknowledgement}

The author is gratefully for the comments on original drafts by anonymous reviewers as their comments enriched the paper. Many thanks to Christa Schier and Sophia Isala for helping with data coding, entry and frequency table production. The author further, acknowledge the willingness of the farmers and various project managers to provider information needed during the survey. Finally, it's the author's indebtedness to the university of Namibia for the financial support, which made it possible to collect the data from the various green schemes projects in the country.

\section{Reference}

Ayelew, A., Deininger, K., \& Duponchel, M. (2014). Credit constraints and agricultural productivity: Evidence from rural Rwanda. The Journal of Development studies, 50(5), 649-665. 
https://doi.org/10.1080/00220388.2014.887687

Binswanger, H. P., \& Deininger, K., (1997). Explaining agricultural and agrarian policy in developing countries. Journal of Economic Literature, xxxv, 1958-2005.

Binswanger, H. P., \& van den Brink, R. (2005). Credit for small farmers in Africa revisited. Saving and Development NO. 3 -xxix.

Binswanger-Mkhize, P. H. (2015). From failure to success in South African Land Reform. African Journal of Agriculture and Resource Economics, 9(4), 253-269.

Bresciani, F., \& Valdes, A. The role of agriculture in poverty reduction: a synthesis of the country case studies.

Dorward, R. A., Kirsten, F. J., Were Omamo, S., Poulton, C. \& Vink, (2009). Institutions and Agricultural Development Challenges in Africa in Kirsten et al 2009 (Ed.) Institutional Economics Perspectives on African Agricultural Development, international food policy research institute, Washington, D.C

Druilhe, Z., \& Barreiro-Hurle J. (2012). Fertilizer subsidies in sub-Saharan Africa, ESA working paper No. 12-04. Food and Agriculture Organization of the United Nations.

Feder, G., Onchan, T., \& Raparla, R. (1988). Collateral, Guaranties and rural credit in developing countries: Evidence from Asia, Agricultural Economics, 2, 231-245. https://doi.org/10.1016/0169-5150(88)90005-9

Government Republic of Namibia, [GRN]. (2008). Green Scheme Policy. Ministry of Agriculture Water and Forestry, Windhoek.

Mashindano, O., Kayunze, K., da Corta, L., \& Maro, F., (2011). Agricultural growth and poverty reduction in Tanzania 2000-2010: Where has agriculture worked for the poor and what can we learn from this? Chronic Poverty Research Centre, working paper No. 208.

Namibia Statistic Agency, (2012). Poverty Dynamics in Namibia: A Comparative study using the 1993/4, 2003/4 and 2009/10 Namibia Household and Income Expenditure Survey. Namibia Statistic Agency, Windhoek.

\section{Copyrights}

Copyright for this article is retained by the author(s), with first publication rights granted to the journal.

This is an open-access article distributed under the terms and conditions of the Creative Commons Attribution license (http://creativecommons.org/licenses/by/3.0/). 